\title{
A Novel Polyurethane-based Root Canal-obturation Material and Urethane Acrylate-based Root Canal Sealer-Part I: Synthesis and Evaluation of Mechanical and Thermal Properties
}

\author{
Kuo-Huang Hsieh, BS, MS, PhD, * Ken-Hsuan Liao, BS, MS, ${ }^{*}$ Eddie Hsiang-Hua Lai, ${ }^{\dagger}$ \\ Bor-Shiunn Lee, DDS, MS, PhD, ${ }^{\dagger}$ Chung-Yi Lee, DDS, MS, ${ }^{+}$and Chun-Pin Lin, DDS, MS, PhD ${ }^{*+}$
}

\begin{abstract}
Resilon (RealSeal; SybronEndo, Orange, CA) has been developed as an alternative to gutta percha, but its advantages over gutta percha remain controversial. In this study, we developed a novel zinc oxide/thermoplastic polyurethane (ZnO/TPU) composite root canalfilling material and a visible-light curable urethaneacrylate/tripropylene glycol diacrylate (UA/TPGDA) root canal sealer. The mechanical and thermal properties of the ZnO/TPU composite were compared with those of gutta percha and Resilon. Results showed that the tensile strength and elastic modulus of the ZnO/TPU composite were markedly higher than those of gutta percha and Resilon. The melting points of all three materials were similar; however, the enthalpy change and specific heat of $\mathrm{ZnO} / \mathrm{TPU}\left(9.4 \mathrm{~J} / \mathrm{g}, 0.7 \mathrm{~J} / \mathrm{g}^{\circ} \mathrm{C}\right.$ ) were close to those of gutta percha $\left(10.9 \mathrm{~J} / \mathrm{g}, 0.7 \mathrm{~J} / \mathrm{g}^{\circ} \mathrm{C}\right)$ but lower than those of Resilon $\left(28.9 \mathrm{~J} / \mathrm{g}, 1.3 \mathrm{~J} / \mathrm{g}^{\circ} \mathrm{C}\right)$. The results indicate that $\mathrm{ZnO} / \mathrm{TPU}$ composite exhibits better mechanical strength than Resilon, and its combination with UA/TPGDA sealer has excellent potential to be used as a root canal-filling material. (J Endod 2008;34: 303-305)
\end{abstract}

\section{Key words}

Mechanical property, root canal obturation, thermal property, zinc oxide/thermoplastic polyurethane composite

From the *Institute of Polymer Science and Engineering, National Taiwan University, Taipei, Taiwan; and ${ }^{\top}$ School of Dentistry and Graduate Institute of Clinical Dentistry, College of Medicine, National Taiwan University and National Taiwan University Hospital, Taipei, Taiwan.

Supported by the National Science Council of Taiwan grant no. NSC95-2622-E-002-020-CC3.

Address requests for reprints to $\mathrm{Dr}$ Chun-Pin Lin, School of Dentistry and Graduate Institute of Clinical Dentistry, College of Medicine, National Taiwan University, No. 1, Chang-Te Street, Taipei 10016, Taiwan. E-mail address: pinlin@ntu.edu.tw. 0099-2399/\$0 - see front matter

Copyright (C) 2008 by the American Association of Endodontists.

doi:10.1016/j.joen.2007.12.006
Tisinas he objectives of root canal obturation are to eliminate leakage from the oral cavity or the periradicular tissues and to achieve fluid-tight seals along the dentinal wall (1). The conventional obturation materials commonly used in endodontics are gutta percha and root canal sealers. However, gutta percha has no dentinal adhesion, lacks sufficient rigidity, and shrinks during cooling or solvent evaporation (2). A new polymer-based obturation material, Resilon (RealSeal; SybronEndo, Orange, CA,) has been developed to replace gutta-percha. By combining methacrylate-based resin sealers with Resilon, the manufacturer claimed that a monoblock-bonding concept could be achieved for the obturation of root canals. Resilon has been shown to exhibit less microbial leakage (3) and higher bond strength to root canal dentin (4), reduce periapical inflammation (5), and enhance fracture resistance of endodontically treated teeth (6) compared with gutta percha. However, some studies reported undesirable properties of Resilon including low push-out bond strength $(2,7,8)$ and low cohesive strength plus stiffness $(9)$. In addition, Resilon could not achieve a complete hermetic apical seal (10). These results indicate that a more appropriate material for root canal obturation still needs to be developed.

The authors have developed a novel polyurethane-based composite to serve as a root canal obturation material and a visible-light curable urethane-acrylate/tripropylene glycol diacrylate (UA/TPGDA) oligomer to serve as a root canal sealer. The composite is composed of thermoplastic polyurethane (TPU) and zinc oxide (ZnO). TPU exhibits good abrasion resistance, tear strength, and shock resorption (11). It has also been used as the biomaterial in artificial blood vessels for more than 20 years because of its good biocompatibility $(12,13)$. This study had two purposes: (1) synthesis and evaluation of mechanical and thermal properties of $\mathrm{ZnO} / \mathrm{TPU}$ composite root canal obturation material and UA/TPGDA sealer and (2) evaluation of the push-out bond strength of the new system. The mechanical and thermal properties of the $\mathrm{ZnO}$ / TPU composite, such as tensile strength, elastic modulus, melting point, enthalpy change, and specific heat, were compared with gutta percha and Resilon. The results of the push-out bond strength test were presented in a subsequent study.

\section{Materials and Methods \\ Preparation of Zno/TPU Composite as a Root Ganal-Filling Material}

Polybutyleneadipate (PBA, molecular weight: 2,000, Taichin Co, Kaohsiung, Taiwan), 1,6-diisocyanatohexane (HDI; Acros Organics, Geel, Belgium), and 1,4-butanediol (1,4-BD, Acros Organics) were mixed in 1:1.12:0.1 molar ratios, dissolved in acetone, and reacted in $50^{\circ} \mathrm{C}$ reactors for 2 hours to form TPU. The product was stirred at $0.1 \mathrm{~atm}$ for 48 hours to remove acetone, and then $70 \mathrm{wt} \%$ of zinc oxide (ZnO, Acros Organics) was added at $120^{\circ} \mathrm{C}$ to form $\mathrm{ZnO} / \mathrm{TPU}$ composite. All materials used in this study were reagent grade and were directly used without further purification.

\section{Preparation of Urethane Acrylate/Tripropylene Glycol Diacrylate Root Ganal Sealer}

2-Hydroxylethylmethacrylate (HEMA, Acros Organics) was mixed with isophorone diisocyanate (IPDI; Double Bond Chemical, Taipei, Taiwan) in a 1:1 molar ratio, dissolved in acetone, and reacted in $50^{\circ} \mathrm{C}$ reactors for 3 hours to form IPDI-modified 
TABLE 1. Mechanical and Thermal Properties (Mean \pm Standard Deviation) of the ZnO/TPU Composite, Gutta Percha, and Resilon $(n=5)$

\begin{tabular}{lccc}
\hline & ZnO/TPU composite & Gutta percha & Resilon \\
\hline Tensile strength $(\mathrm{MPa})$ & $22.6 \pm 2.8$ & $6.0 \pm 1.2^{*}$ & $8.1 \pm 2.3^{*}$ \\
Elastic modulus $(\mathrm{MPa})$ & $137.6 \pm 27.6$ & $78.7 \pm 23.4^{*}$ & $86.6 \pm 42.2^{*}$ \\
Melting point $\left({ }^{\circ} \mathrm{C}\right)$ & $63.3 \pm 0.3$ & $61.3 \pm 0.4$ & $64.2 \pm 0.2$ \\
Enthalpy change $(\mathrm{J} / \mathrm{g})$ & $9.4 \pm 0.5$ & $10.9 \pm 0.6$ & $28.9 \pm 0.3$ \\
Specific heat $\left(\mathrm{J} / \mathrm{g}^{\circ} \mathrm{C}\right)$ & $0.7 \pm 0.3$ & $0.7 \pm 0.1$ & $1.3 \pm 0.1$ \\
\hline
\end{tabular}

*The mechanical properties of gutta percha and Resilon were cited from reference 9.

HEMA. PBA with molecular weight 500 was then added in 1:1 molar ratio and reacted for 3 hours to form urethane acrylate (UA). The mixture was stirred at $0.1 \mathrm{~atm}$ for 48 hours to remove acetone. Subsequently, UA was diluted with tripropylene glycol diacrylate (TPGDA; AGI Co, Taiwan) in 8:2 weight ratios. D, L-camphorquinone (CQ, Acros Organics) and ethyl 4-dimethylaminobenzoate (EDMAB, Acros Organics) were used as photoinitiators, whereas 2,2-Azobis-isobutyronitrile (AIBN; Showa Chemical Co, Tokyo, Japan) was used as thermal initiator. All three components were added in 1 per hundred parts of resin.

\section{Measurement of Mechanical and Thermal Properties}

The tensile strength and elastic modulus of $\mathrm{ZnO} / \mathrm{TPU}$ composite were determined according to American Society for Testing and Materials (ASTM) D412-98a (14) and measured with a universal testing machine (Instron Corp, Canton, MA) at a crosshead speed of $0.5 \mathrm{~mm} /$ min. The melting point and enthalpy change of $\mathrm{ZnO} / \mathrm{TPU}$ composite, gutta percha (Obtura II; Obtura-Spartan, Fenton, MO), and Resilon were measured by using a differential scanning calorimeter (DSC) (DSC2010; TA-Instrument, Crawley, UK) by heating to $110^{\circ} \mathrm{C}$ at a rate of $10^{\circ} \mathrm{C} / \mathrm{min}$. The enthalpy change and the melting point could be identified from the DSC diagram by the area and the position of the melting peak. Specific heat was determined by DSC according to ASTM E1269-95 (15). The sapphire was used as the standard to produce a standard line, and the formulation used to calculate the specific heat capacity $\left(\mathrm{C}_{\mathrm{p}} ; \mathrm{J} / \mathrm{g}^{\mathrm{O}} \mathrm{C}\right)$ was the following:

$$
\mathrm{C}_{\mathrm{p}}=\left[\frac{60 . \mathrm{E}}{\mathrm{Hr}}\right] \cdot \frac{\Delta \mathrm{y}}{\mathrm{m}}
$$

E represents the correction factor of the DSC stove (dimensionless), $\mathrm{H}_{\mathrm{r}}$ the heating rate $\left({ }^{\circ} \mathrm{C} / \mathrm{min}\right), \Delta \mathrm{y}$ the heat flow difference between the

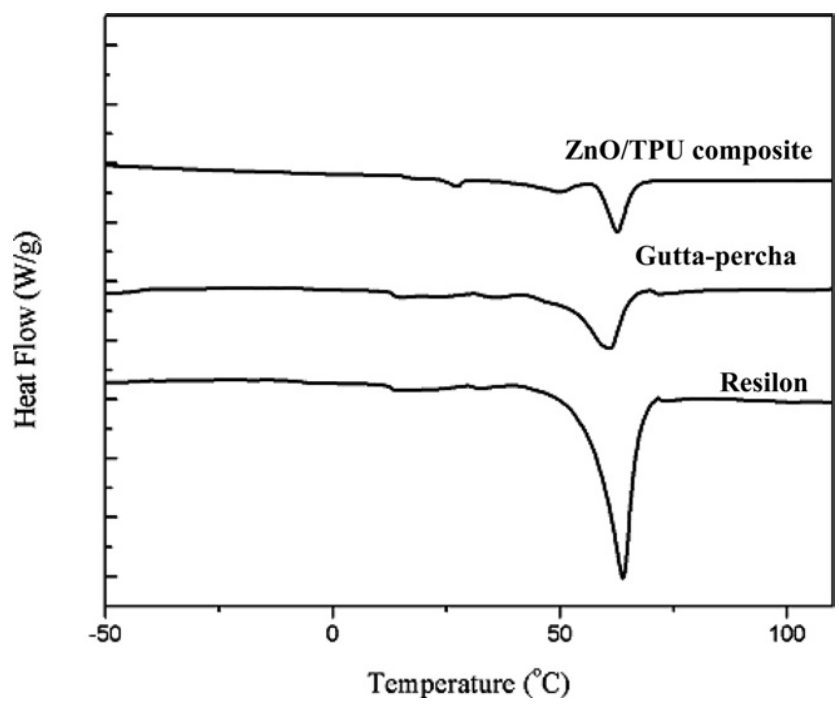

Figure 1. Melting point and enthalpy change for $\mathrm{ZnO} / \mathrm{TPU}$ composite, gutta percha, and Resilon. standard line and the base line of sample $(\mathrm{mW})$, and $\mathrm{m}$ the sample weight (mg).

\section{Results}

The results of the evaluation of the mechanical and thermal properties of ZnO/TPU composite, gutta percha, and Resilon are listed in Table 1. The tensile strength of ZnO/TPU composite $(22.6 \pm 2.8 \mathrm{MPa})$ was much higher than that of gutta percha $(6.0 \pm 1.2 \mathrm{MPa})$ and Resilon $(8.1 \pm 2.3 \mathrm{MPa})(9)$. The elastic modulus of $\mathrm{ZnO} / \mathrm{TPU}$ composite $(137.6 \pm 27.6 \mathrm{MPa})$ was also markedly higher than that of gutta percha $(78.7 \pm 23.4 \mathrm{MPa})$ and Resilon $(86.6 \pm 42.2 \mathrm{MPa})(9)$. DSC analysis (Fig. 1) revealed that the melting points of $\mathrm{ZnO} / \mathrm{TPU}$ composite $(63.3 \pm$ $\left.0.3^{\circ} \mathrm{C}\right)$, gutta percha $\left(61.3 \pm 0.4^{\circ} \mathrm{C}\right)$, and Resilon $\left(64.2 \pm 0.2^{\circ} \mathrm{C}\right)$ were similar. However, the enthalpy changes (Fig. 1) of both the $\mathrm{ZnO} / \mathrm{TPU}$ composite $(9.4 \pm 0.5 \mathrm{~J} / \mathrm{g})$ and gutta percha $(10.9 \pm 0.6 \mathrm{~J} / \mathrm{g})$ were markedly lower than that of Resilon $(28.9 \pm 0.3 \mathrm{~J} / \mathrm{g})$. As shown in Figure 2 , the $\mathrm{ZnO} / \mathrm{TPU}$ composite $\left(0.7 \pm 0.3 \mathrm{~J} / \mathrm{g}^{\circ} \mathrm{C}\right)$ and gutta percha $\left(0.69 \pm 0.11 \mathrm{~J} / \mathrm{g}^{\circ} \mathrm{C}\right)$ exhibited similar specific heat values that were markedly lower than that of Resilon $\left(1.3 \pm 0.1 \mathrm{~J} / \mathrm{g}^{\circ} \mathrm{C}\right)$.

\section{Discussion}

In this study, we synthesized TPU by mixing PBA, HDI, and 1,4-BD in 1:1.12:0.1 molar ratios that were determined from the results of our preliminary studies. The optimal mechanical and thermal properties of TPU can be obtained by adjusting the hard-/soft-segment ratio in the main chain. The soft segments, which arise from high-molecularweight polyols (ie, PBA), provide rubbery properties. The hard segments, which are composed of diisocyanate (ie, HDI) and low-molecular-weight diols (ie, 1,4-BD), serve as physical crosslinking agents and crystalline chains (16). The inclusion of an ester-type polyol such as

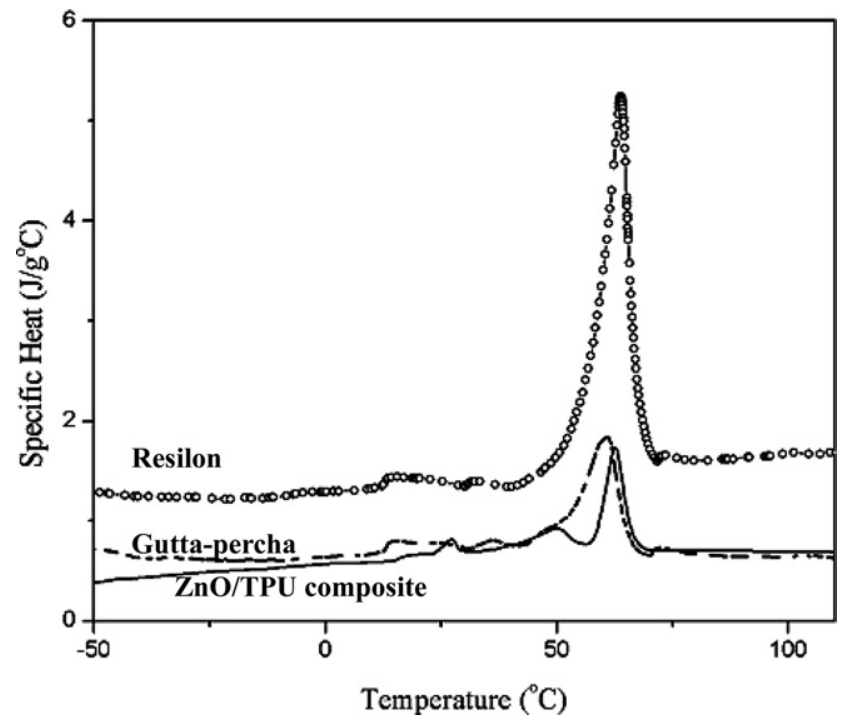

Figure 2. Specific heat capacity for $\mathrm{ZnO} / \mathrm{TPU}$ composite, gutta percha, and Resilon. 
PBA in TPU could contribute to higher mechanical strength (17). In addition, HDI exhibits aliphatic chain with smaller sterical stabilization, which is conducive to the alignment of polymer chains. However, adding a greater amount of HDI would make the TPU chains less mobile and would subsequently impede the amount of $\mathrm{ZnO}$ filler that could be added. Therefore, PBA was selected as the polyol in this study, and it was mixed with HDI in 1:1.12 molar ratios.

The UA/TPGDA sealer was developed to be compatible with $\mathrm{ZnO} /$ TPU filling material by modifying urethane group (-NHCOO-) with PBA. Both the side chain of UA/TPGDA sealer and the main chain of TPU exhibit urethane group and PBA. Moreover, PBA is a hydrophobic structure that can provide chemical compatibility between UA/TPGDA sealer and $\mathrm{ZnO} / \mathrm{TPU}$ cone. Furthermore, the formation of hydrogen bonds between the hydrogen and nitrogen atoms on the urethane groups of UA/TPGDA sealer and the Zn0/TPU cone enhances the adhesion of UA/TPGDA sealer to ZnO/TPU cone.

Compared with the mechanical strengths of gutta percha and Resilon, ZnO/TPU composite prominently exhibited higher tensile strength and elastic modulus (Table 1). The elastic modulus of gutta percha is only 78.7 MPa (9), and it cannot reinforce the root because it does not adhere to the root canal wall. Although Resilon has been reported to exhibit the ability to reinforce the root against fracture (6), the bond strength of Resilon is low (0.5 MPa) (2) and its elastic modulus (86.6 $\mathrm{MPa}$ ) is too low to reinforce the root (9). The elastic modulus and tensile strength of dentin are about $16 \mathrm{GPa}(18)$ and 36 to $100 \mathrm{MPa}$ (19), respectively. Theoretically, a material bonded to dentin should have a similar elastic modulus to that of dentin to avoid stress concentration along the interface. Consequently, the higher elastic modulus of $\mathrm{ZnO} / \mathrm{TPU}$ composite $(137.6 \mathrm{MPa})$ should contribute a greater reinforcing effect to the roots. The tensile strength of $\mathrm{ZnO/TPU}$ composite (22.6 $\mathrm{MPa})$ is also closer to that of dentin than those of gutta percha $(6.0$ $\mathrm{MPa}$ ) and Resilon (8.1 MPa). Nevertheless, further study is needed to determine the actual bond strength of $\mathrm{ZnO} / \mathrm{TPU}$ composite to dentin.

The results on melting points, enthalpy changes (Fig. 1), and specific heat (Fig. 2) of gutta percha and Resilon in this study are consistent with previous findings (20). Compared with the thermal properties of gutta percha and Resilon, ZnO/TPU composite exhibited a melting point value that was similar to gutta percha and Resilon but markedly showed lower enthalpy change and specific heat than Resilon (Table 1). Enthalpy change means the quantity of heat released or absorbed during phase transition. For ZnO/TPU composite, the enthalpy change only depends on the matrix component because the inorganic filler does not melt at the same temperature. The specific heat represents the quantity of heat required to change the temperature of a unit mass $1^{\circ}$. The lower enthalpy change and specific heat of $\mathrm{ZnO} / \mathrm{TPU}$ composite in comparison with those of Resilon indicate that less heat is required to thermoplasticize $\mathrm{ZnO} / \mathrm{TPU}$ composite during warm vertical compaction.

$\mathrm{ZnO/TPU}$ composite is a polymer-based root canal-filling material with superior mechanical properties to gutta percha and Resilon. The results of specific heat and enthalpy change analyses; the thermal energy required to thermoplasticize $\mathrm{ZnO} / \mathrm{TPU}$ composite is approximately that of gutta percha but lower than that of Resilon. Further studies to evaluate the performance of this new material such as push-out bond strength and a microleakage test as well as the tissue toxicity of these materials before their use in clinical treatments are warranted.

\section{References}

1. Johnson WT, Gutmann JL. Obturation of the cleaned and shaped root canal system. In: Cohen S, Hargreaves KM, eds. Pathways of the Pulp. 9th ed. St Louis: Mosby; 2006:358-99.

2. Gesi A, Raffaelli 0, Goracci C, Pashley DH, Tay FR, Ferrari M. Interfacial strength of Resilon and gutta-percha to intraradicular dentin. J Endod 2005;31:809-13.

3. Shipper G, Orstavik D, Teixeira FB, Trope M. An evaluation of microbial leakage in roots filled with a thermoplastic synthetic polymer-based root canal filling material (Resilon). J Endod 2004:30:342-7.

4. Skidmore LJ, Berzins DW, Bahcall JK. An in vitro comparison of the intraradicular dentin bond strength of Resilon and gutta-percha. J Endod 2006;32:963-6.

5. Shipper G, Teixeira FB, Arnold RR, Trope M. Periapical inflammation after coronal microbial inoculation of dog roots filled with gutta-percha or Resilon. J Endod 2005;31:91-6.

6. Teixeira FB, Teixeira EC, Thompson JY, Trope M. Fracture resistance of roots endodontically treated with a new resin filled material. J Am Dent Assoc 2004; 135:646-52.

7. Sly MM, Moore BK, Platt JA, Brown CE. Push-out bond strength of a new endodontic obturation system (Resilon/Epiphany). J Endod 2007;33:160-2.

8. Ungor M, Onay E0, Orucoglu H. Push-out bond strengths: the Epiphany-Resilon endodontic obturation system compared with different pairings of Epiphany, Resilon, AH Plus and gutta-percha. Int Endod J 2006;39:643-7.

9. Williams C, Loushine RJ, Weller RN, Pashley DH, Tay FR. A comparison of cohesive strength and stiffness of Resilon and gutta-percha. J Endod 2006;32:553-5.

10. Tay FR, Loushine RJ, Weller RN, et al. Ultrastructural evaluation of the apical seal in roots filled with a polycaprolactone-based root canal filling material. J Endod 2005;31:514-9.

11. Boretos JW, Pierce WS. Segmented polyurethane: a new elastomer for biomedical applications. Science 1967;158:1481-2.

12. King M, Zhang Z. Quantitative analysis of the surface morphology and textile structure of the Polyurethane Vascugraft ${ }^{\circledR}$ arterial prosthesis using image and statistical analyses. Biomaterials 1994;15:621-7.

13. Huang B, Marios Y. Cellular reaction to the Vascugraft ${ }^{\circledR}$ polyesterurethane vascular prosthesis: in vivo studies in rats. Biomaterials 1992;13:209-16.

14. ASTM D-412-98a. The American Society for Testing and Materials (ASTM): Standard test methods for vulcanized rubber and thermoplastic elastomers. Tension, 2002.

15. ASTM E1269-95. The American Society for Testing and Materials (ASTM): Standard test method for determining specific heat capacity by differential scanning calorimetry, 2000.

16. Hsieh TT, Hsieh KH, Simon GP, Tiu C. Interpenetrating polymer networks of 2-hydroxyethyl methacrylate terminated polyurethanes and polyurethanes. Polymer 1999; $40: 3153-63$

17. Xiu Y, Wang D, Hu C, Ying S, Li J. Morphology-property relationship of segmented polyurethaneurea: Influences of soft-segment structure and molecular weight. J Appl Polym Sci 1993;48:867-9.

18. Kinney JH, Balooch M, Marshall GW, Marshall SJ. A micromechanics model of the elastic properties of human dentine. Arch Oral Biol 1999;44:813-22.

19. Sano H, Ciucchi B, Matthews WG, Pashley DH. Tensile properties of mineralized and demineralized human and bovine dentin. J Dent Res 1994;73:1205-11.

20. Miner MR, Berzins DW, Bahcall JK. A comparison of thermal properties between gutta-percha and a synthetic polymer based root canal filling material (Resilon). J Endod 2006;32:683-6. 